\title{
Fibrinolytic properties of basidiomycetes Coprinus lagopides and Funalia trogii
}

\author{
Sergei Sorokin ${ }^{1,}$, Mark Shamtsyan ${ }^{1}$, and Nicolai Petrishchev ${ }^{2}$ \\ ${ }^{1}$ Saint-Petersburg State Institute of Technology, 198013, 26, Moskovskii pr., St. Peterburg, Russia \\ ${ }^{2}$ Pavlov First Saint Petersburg State Medical University, 197022, 6-8, L'va Tolstogo st., St. \\ Petersburg, Russia
}

\begin{abstract}
Currently, the search continues for fibrinolytic and thrombolytic drugs that quickly dissolve blood clots and do not have side effects. One of the directions of these studies is the production of fibrinolytic enzymes from deep cultures of basidiomycetes. This work examines the fibrinolytic activity of culture liquids obtained from two cultures of saprophytic basidiomycetes: Coprinus lagopides and Funalia trogii in comparison with the commercial thrombolytic drug Actilyse.
\end{abstract}

\section{Introduction}

Currently, the widespread prevalence of cardiovascular diseases is becoming the cause of death and disability in many countries around the world. Such diseases are often accompanied by thromboembolic complications, which pose a risk to human health. According to the World Health Organization (WHO), coronary heart disease and stroke were the most common causes of death in 2015. Globally, out of 56.4 million deaths, these diseases have killed a total of 15 million people. Over the past 15 years, cardiovascular diseases have remained the leading causes of death in the world [1].

In this regard, one of the most important tasks of modern biotechnology and medicine is the increase in alternative sources of antithrombotic agents, the search for new biologically active compounds and the production of drugs that dissolve blood clots, prevent their formation, and also make it possible to quickly and accurately diagnose violations of the human hemostasis system [2].

A priority area for biotechnology and mycology is the study and use of basidiomycetes for the production of biologically active compounds, including medicinal ones (enzymes, polysaccharides, lipids, organic acids and vitamins). The resulting compounds are less toxic and can be more pharmacologically active than the products of chemical synthesis. However, the lack of a sufficient amount of information about the cultivation of higher fungi and the substances they produce, the industrial production of drugs based on them is just beginning to improve [3].

The emergence of interest in the study of basidiomycetes as possible producers of proteolytic enzymes is a consequence of the lack of animal raw materials and the imperfection of microbial preparations.

* Corresponding author: sersorock@yandex.ru 
The search for enzymes for the food and medical industry among basidiomycetes is determined by two circumstances: the absence of sporulation in culture, which reduces the risk of occupational diseases in industrial conditions, and the presence of a large number of edible mushrooms [3].

Fibrinolytic enzymes, which are the most important category of the proteolytic group of enzymes, are of great medical importance. In the $60 \mathrm{~s}$, researchers drew attention to fungal fibrinolytic enzymes, which could be used for the conservative treatment of thromboembolic and other diseases associated with blood clotting. By the type of action and by their nature, these enzymes are close to enzymes of the proteinase type, for example, trypsin. Many of them have weak caseinolytic activity but are highly active in the hydrolysis of fibrin. Some stimulate the activity of the fibrinolytic blood systems. These include streptokinase, obtained from Streptococcus haemolytlcum, and tricholysin, from the fungus Trichothecium roseum, while those with fibrinolytic action, but unknown as activators of fibrinolysis in the body of the animal enzyme, were isolated mainly from species of the genus Aspergillus [4].

Therefore, one of the main directions in the development of drugs now is the production of drugs based on fibrinolytic and thrombolytic enzymes. At the same time, of particular interest are the cultures of fungi, which are producers of these enzymes.

The process of blood clotting is based on the formation of a clot of fibrin protein, which closes the damage to the vessel together with blood cells [5]. Under the action of the enzyme thrombin, which is formed from prothrombin, fibrin is formed from the precursor, fibrinogen. Fibrinogen and prothrombin are constantly in a dissolved state in the blood. At the moment of damage to the vessel, coagulation begins. Under the action of blood thromboplastin entering the blood from damaged tissues, the conversion of prothrombin to thrombin begins.

The coagulation process is conventionally divided into 3 phases [6]:

a) the formation of prothrombinase. It can be carried out by two mechanisms - external (flows in the tissues with the formation of tissue prothrombinase) and internal (inside the vessel with the formation of blood prothrombinase);

b) the formation of thrombin (from inactive prothrombin under the influence of prothrombinase);

c) the formation of fibrin (from fibrinogen under the influence of thrombin).

The physiological role of the coagulation system in the body is to finally stop bleeding by tight clogging of damaged vessels with a thrombus. A thrombus consists of a network of fibers consisting of a network of fibrin fibers with trapped blood cells (erythrocytes, platelets, etc.) [6]. The role of other cascades of biochemical reactions is exclusively regulatory.

Thrombin is synthesized as prothrombin, which can be activated. When activated, a cascade of biochemical reactions of the blood coagulation system is launched. Tissue factor is a protein that is present in the cell membranes of all tissues, with the exception of the endothelium and blood. When the endothelium is damaged, blood plasma comes into contact with cells that carry tissue factor, and it activates the external blood coagulation system. [7]

Completion of the formation of a blood clot occurs after the formation of fibrin. After (30-60) minutes, the contraction (retraction) of the formed fibrin thrombus begins. This happens due to the reduction of the myosin and actin filaments of platelets, as well as fibrin filaments under the influence of thrombin and calcium ions. As a result of retraction, the clot is compressed into a dense mass, the thrombus thickens and tightens the edges of the wound, which facilitates its closure by connective tissue cells [7].

During normal operation of the blood coagulation system, after stopping bleeding and tissue accretion, the thrombus dissolves during fibrinolysis. However, over the past 100 
years, cardiovascular diseases have become the most fatal, and thrombosis is one of the main causes of death. Various thrombolytic and fibrinolytic drugs are used to destroy and prevent the formation of blood clots. One of them is the recombinant single-chain drug alteplase - is produced under the name "Actilyse", the two-chain drug is called "Duteplase". They are based on tissue plasminogen activator - a serine protease produced by endothelial cells [8]. A distinctive feature of alteplase is the high selectivity of action on plasminogen, which is associated with fibrin. Unlike streptokinase, alteplase is a fibrin-selective drug, therefore, in terms of thrombolytic efficiency, it is superior to streptokinase and urokinase. Alteplase rarely causes bleeding and lacks antigenic properties $[8,9]$.

Fibrinolytic drugs are able to dissolve the formed fibrin thrombus, in contrast to anticoagulants and antiplatelet drugs, which are used to prevent thrombus formation. Thanks to fibrinolytics, normal blood flow is restored in the ischemic zone of the affected organ and its functioning is normalized [9].

Fibrinolytic drugs are drugs that dissolve blood clots inside blood vessels. Such drugs may have a fibrin-selective effect, acting only on plasminogen associated with fibrin inside blood clots; or non-fibrin-selective, activating plasminogen, not only associated with a thrombus, but also plasminogen in the blood. The former includes drugs such as alteplase, reteplase, tenecteplase, etc. The latter include streptokinase, urokinase, anisteplase [10].

In modern mycology and biotechnology, the priority is the production of biologically active compounds and medicinal products using higher basidiomycetes. Compared with chemically synthesized products, these compounds are more pharmacologically active and less toxic. However, at the moment, many information about the cultivation of mushrooms has not yet been obtained, but are at the stage of search, therefore, the industrial production of both the mushrooms themselves and biologically active preparations based on them is just beginning to improve [3,11].

Interest in basidiomycetes as possible sources of proteolytic enzymes has developed due to the shortage of animal raw materials and imperfection of microbial preparations. Among the higher mushrooms, there are a large number of edible ones; moreover, the absence of sporulation in culture reduces the risk of occupational diseases in production conditions [2]. Preparations of microbial origin in the field of thrombolytics have serious side effects associated with a high level of general, non-specific proteolysis, which hinders their widespread use in medical practice. In this regard, it is necessary to look for enzymes for food and medical purposes among other sources, for example, higher basidiomycetes [3].

The first person who came up with the idea to use fungal enzymes to fight blood clots was Stephanini M. He received the first injectable drug of this type "Aspergillin O" from Aspergillus oryzae, which is a neutral protein precipitated by heavy metal salts $\left(\mathrm{Cu}^{2+}, \mathrm{Zn}^{2+}\right.$, $\left.\mathrm{Cd}^{2+}\right)$. A similar drug was obtained in the Soviet Union from a strain of the same species. The thermolabile drug was named Aspergillin and had differences in the optimal $\mathrm{pH}$ value, type of action, molecular weight and amino acid composition [12].

If we talk about the proteolytic enzymes of basidiomycetes in general, they have long been successfully used in the food industry. To date, there are data on the ability of basidiomycetes to produce milk-clotting enzymes [13]. For example, from cultures of Irpex lacteus, Fomitopsis pinicola and Russula decolorans, proteinases that replace rennet, which are used in cheese making, have been isolated and studied. Proteases of fruiting bodies of oyster mushroom (Pleurotus ostreatus) are also promising for use [14].

Proteolytic enzymes of some basidiomycetes may be of interest as fibrinolytic and thrombolytic agents. These are proteinases from Flammulina velutipes, Coprinus domecticus, C. Cinereus, Cerrena unicolor. High proteolytic activity in Pleurotus ostreatus, Armillaria mellea, Panus tigrinus, Lyophyllum ulmarium, etc. [15, 16].

Proteolytic enzymes, or proteases, can be found in almost all living organisms, but fungi and bacteria are more preferred sources for the isolation of proteases. This is due to their 
rapid growth in culture and the possibility of genetic manipulation. Fungi synthesize proteases in a more diverse way than bacteria. Unlike bacterial proteases, fungal proteases have a low reaction rate and are less tolerant to high temperatures; however, they are active at $\mathrm{pH}$ (4-13) and exhibit a wide substrate specificity [13]. It has been established that basidial macromycetes (Basidiomycota division) are able to synthesize serine, thiol, aspartyl metalloproteinases, which are also found in fungi of other systematic groups in different proportions. However, in general, aspartyl proteinases have proteolytic (thrombotic, fibrin, caseinolytic, and milk-clotting) activity [17]. In vitro, fibrinolytic activity was detected in the culture fluid (CL) of 9 species of 12 strains of coprinoid fungi. The most active producers of extracellular fibrinolytic enzymes were the mycelium of Coprinus and Coprinellus species. The culture fluid of $C$. comatus and C. domesticus increased the rate of fibrinolysis by $25 \%$ and $21 \%$, respectively. The activity of mycelium extracts was to a large extent lower than the activity of the culture liquid [13].

In this regard, the task appears to develop preparations based on fibrin and thrombolytic enzymes and to improve methods for their preparation. This direction is quite promising, as it represents an alternative in the medical field and can give impetus to the development of drugs based on enzymes of basidiomycetes. Therefore, studies on this topic are of particular interest and practical importance.

\section{Materials and methods}

Cultures of the higher basidiomycetes Funalia trogii and Coprinus lagopides, provided by the Museum of Cultures of the Department of Microbiological Synthesis Technology of the St. Petersburg State Technical University (TU), were used as materials (objects) of the study.

At the first stage, for the successful implementation of the process of growing basidiomycetes, it is important to properly prepare the inoculum - inoculum. Prior to sowing on a liquid medium, cultures of higher fungi are stored on solid nutrient media of various compositions, depending on the biological characteristics of the strain. The cultures were grown in test tubes on wort agar at a temperature of (26-28) ${ }^{\circ} \mathrm{C}$ for (7-10) days (until the surface of the slant agar was completely overgrown).

At the next stage (2-3) pieces of mycelium (about $50 \mathrm{~mm} 2$ in size) were subcultured from the agar medium into $0.5 \mathrm{~L}$ Erlenmeyer conical flasks with $150 \mathrm{ml}$ of nutrient medium. Glass beads (7-10) $\mathrm{mm}$ in diameter were poured onto the bottom of the flasks.

The inoculum was grown under stationary conditions at a temperature of $(26-28){ }^{\circ} \mathrm{C}$ for 7 days until the surface of the medium was completely overgrown with a film of mycelium.

The grown surface inoculum was crushed using glass beads while shaking the flasks on a rocking chair. The resulting suspension was used as seed in the fermentation step. Then they proceeded to the second stage - deep cultivation.

The second stage is the cultivation of inoculum on rocking chairs in a liquid medium in Erlenmeyer flasks by a deep method. Flasks are inoculated with a culture of a suspension of ground surface inoculum. To obtain a homogeneous inoculum, the flasks must be inoculated with the same number of Basidiomycetes, grown for the same period of time and at the same temperature. In the case of submerged cultivation, the cultures are inoculated into flasks with a liquid medium and grown on a rotary shaker until a noticeable biomass is formed [3]. Submerged cultivation was carried out in $0.75 \mathrm{~L}$ Erlenmeyer flasks with $100 \mathrm{ml}$ of nutrient medium on a rotary shaker $(230 \mathrm{~min}-1)$ at $(26-28){ }^{\circ} \mathrm{C}$ for 7 days. The cultivation was carried out on glucose-peptone medium. The composition of the culture medium is shown in Table 1. After cultivation, the culture liquid was separated from the biomass by filtration through a paper filter. Then the filtrate was subjected to ultrafiltration. We used a 
non-flowing ultrafiltration cell of the "FK 01 - 1000" brand with a volume of $200 \mathrm{ml}$, as well as an ultrafiltration membrane "MIFIL PA - 20".

Table 1. Composition of the nutrient medium for the cultivation of higher fungi.

\begin{tabular}{|c|c|}
\hline Component & Quantity, g/1 \\
\hline Glucose & 10 \\
\hline Peptone & 2.5 \\
\hline $\mathrm{NaCl}$ & 0.5 \\
\hline $\mathrm{KH} 2 \mathrm{PO} 4$ & 0.6 \\
\hline $\mathrm{K} 2 \mathrm{HPO} 4$ & 0.4 \\
\hline $\mathrm{MgSO} 4$ & 0.5 \\
\hline $\mathrm{CaCl} 2$ & 0.05 \\
\hline Yeast extract & 2 \\
\hline
\end{tabular}

Determination of fibrinolytic activity was carried out using a set of reagents for determining the amount of plasminogen ChromoTech-Plasminogen. The quantitative determination of the protein formed during the cultivation was carried out according to the Lowry method. Separately, the obtained extracts of the culture fluid of mushrooms were compared with "Actilyse" - the commercial name of the thrombolytic and fibrinolytic drug alteplase - a single-chain recombinant tissue plasminogen activator.

To determine the specific fibrinolytic activity, the protein concentration in the preparations was measured by the Lowry method.

\section{Results}

After cultivation and filtration fibrinolytic activities and protein concentrations in culture liquids of both cultures were measured. The results of the comparison of specific fibrinolytic activity with commercial drug are presented in Table 2.

Table 2. Comparison of specific fibrinolytic activity.

\begin{tabular}{|c|c|}
\hline Preparations & $\begin{array}{c}\text { Specific fibrinolytic activity, } \\
\mathrm{U} / \mathrm{mg}\end{array}$ \\
\hline Coprinus lagopides & $62.5 \pm 1.4$ \\
\hline Funalia trogii & $89.3 \pm 1.5$ \\
\hline "Actilyse" & $33.9 \pm 1.2$ \\
\hline
\end{tabular}

A comparison of the fibrinolytic activity of preparations obtained from basidiomycetes with the commercial thrombolytic drug "Actilyse" was carried out. The preparations from higher mushrooms showed higher activity in comparison with the commercial one. The activity of "Actilyse" was $(33.9 \pm 1.2) \mathrm{U} / \mathrm{mg}$, while preparations from cultures of C. lagopides and F. trogii - (62.5 \pm 1.4$) \mathrm{U} / \mathrm{mg}$ and $(89,3 \pm 1.5) \mathrm{U} / \mathrm{mg}$, respectively, which is significantly higher than the commercial drug by $2-3$ times. 
The culture liquid of the preparations was concentrated by ultrafiltration 4 times, then they were dried using freeze-drying. Fibrinolytic activity was measured before and after ultrafiltration, as well as after freeze drying, to determine how each process affects the activity of the resulting preparation. Fibrinolytic activity after each process is presented in table 3 .

Table 3. Fibrinolytic activity of preparations.

\begin{tabular}{|c|c|c|c|c|}
\hline Culture & $\begin{array}{c}\text { Before } \\
\text { ultrafiltration, } \\
\mathrm{U} / \mathrm{ml}\end{array}$ & $\begin{array}{c}\text { After } \\
\text { ultrafiltration, } \\
\mathrm{U} / \mathrm{ml}\end{array}$ & $\begin{array}{c}\text { Fibrinolytic } \\
\text { activity after } \\
\text { freeze drying, } \\
\mathrm{U} / \mathrm{ml}\end{array}$ & $\begin{array}{c}\text { Specific } \\
\text { fibrinolytic } \\
\text { activity, U / mg }\end{array}$ \\
\hline Funalia trogii & $45.0 \pm 1.2$ & $205.0 \pm 1.7$ & $200.5 \pm 1.6$ & $89.3 \pm 1.3$ \\
\hline $\begin{array}{c}\text { Coprinus } \\
\text { lagopides }\end{array}$ & $33.0 \pm 1.2$ & $103.0 \pm 1.6$ & $101.2 \pm 1.5$ & $62.5 \pm 1.4$ \\
\hline
\end{tabular}

\section{Conclusions}

During the work, the presence of fibrinolytic activity in such saprophytic basidiomycetes as Funalia trogii and Coprinus lagopides was shown. When compared with the commercial fibrinolytic drug "Actilyse", it was shown that the fibrinolytic activity of the culture liquids of fungi is almost twice that of the commercial drug. Such a high activity can be caused by the non-fibrin-selective action of the preparations, in contrast to the fibrin-selective action of alteplase, which is the active ingredient in Actilyse.

Preparations were obtained from native solutions of fungi using ultrafiltration and freeze drying. Ultrafiltration increases the fibrinolytic activity of the culture fluid in all studied fungal cultures. After freeze drying, the activity of all drugs decreases in the range of $3-5 \mathrm{U} / \mathrm{ml}$.

\section{References}

1. D.T. Jamison, H. Gelband, S. Horton, Disease Control Priorities: Improving Health and Reducing Poverty. 3rd edition (Washington (DC): The International Bank for Reconstruction and Development / The World Bank, 2017) DOI: 10.1596/978-1-46480527-1_ch4

2. O.A. Kudryavtseva, Ya.E. Dunaevsky, O.V. Kamzolkina, M.A. Belozersky, Mikrobiologiya 77(6), 725-737 (2008) DOI: 10.1134/S0026261708060015

3. S.P. Wasser, Applied microbiology and biotechnology 89(5), 1323-1332 (2011) DOI: 10.1007/s00253-010-3067-4

4. K. I. Fayek, M.S. Foda, M.E. Naggar, Zeitschrift für allgemeine Mikrobiologie 16(6), 417-423 (1976) DOI: 10.1002/jobm.19760160602

5. Z. Xu, N. Chen, S.C. Shadden, J.E. Marsden, M.M. Kamocka, E.D. Rosen, M. Alber, Soft Matter 5(4), 769-779 (2009) DOI: 10.1039/B812429A

6. J.W. Weisel, Journal of Thrombosis and Haemostasis 5, 116-124 (2007) DOI: 10.1111/j.1538-7836.2007.02504.X

7. J. Steffel, T.F. Lüscher, F.C. Tanner, Circulation 113(5), 722-731 (2006) DOI: 10.1161/CIRCULATIONAHA.105.567297

8. S.S. Ramaiah, B. Yan, Cerebrovascular Diseases 36(3), 161-166 (2013) DOI: $10.1159 / 000354162$ 
9. M. Flemmig, M.F. Melzig, Journal of Pharmacy and Pharmacology 64(8), 1025-1039 (2012) DOI: 10.1111/j.2042-7158.2012.01457.x

10. M. Sabovic, H.R. Lijnen, D. Keber, D. Collen, Thrombosis and haemostasis 62(04), 1083-1087 (1989)

11. V.I. Elisashvili, International journal of medicinal mushrooms 14(3), 211-239 (2012) DOI: 10.1615/IntJMedMushr.v14.i3.10

12. E. Genton, L. Pechet, Annals of Internal Medicine 69(3), 625-628 (1968) DOI: 10.7326/0003-4819-69-3-625

13. P.M.D. Souza, M.L.D.A. Bittencourt, C.C. Caprara, M.D. Freitas, R.P.C.D. Almeida, D. Silveira, P.O. Y.M. Fonseca, E.X.F. Filho, A.P. Junior, P.O. Magalhães, Brazilian Journal of Microbiology 46(2), 337-346 (2015) DOI: 10.1590/S1517838246220140359

14. G.V. Lebedeva, M.T. Proskuryakov, Prikladnaya Biokhimiya i Mikrobiologiya 45(6), 690-692 (2009) DOI: 10.1134/S0003683809060088

15. N.P. Denisova, International Journal of Medicinal Mushrooms 12(3), 317-325 (2010) DOI: 10.1615/IntJMedMushr.v12.i3.110

16. M. Shamtsyan, Potential to develop functional food products from mushroom bioactive compounds, Journal of Hygienic Engineering and Design 15, 51-59 (2016)

17. V. Mandujano-González, L. Villa-Tanaca, M.A. Anducho-Reyes, Y. Mercado-Flores, Revista Iberoamericana de Micología 33(2), 76-82 (2016) DOI: 10.1016/j.riam.2015.10.003 